\title{
Organisational Structure and Strategy Implementation: Empirical Evidence from Oil Marketing Companies in Kenya
}

\author{
Musa Mohamed Yabarow \\ Stephen M. A. Muathe \\ Kenyatta University, Kenya
}

\begin{abstract}
The paper aims to investigate the relationship between organisational structure and strategy implementation in oil marketing companies. The study attempts to ascertain the perceptions of the employees regarding the impact of organisational structure on strategy implementation using four organisational variables: hierarchical levels, organisational communication, decision making structures and organisational culture. Based on a sample of 148 respondents working in Kenyan oil marketing companies, the study found that hierarchical levels, organisational communication, decision making structures and organisational culture have a certain influence on strategy implementation. By considering the influence of communication, decision-making, and organisational culture, this study attempts to explore the ways in which organisational structure influences strategy implementation in Kenyan oil marketing companies.
\end{abstract}

Keyword: Organisational Hierarchy; Organisational Structure; Organisational Communication; Decision making; Strategy implementation 


\section{Introduction}

Strategy implementation is the process of putting plans and strategy into actions in order to accomplish the long-term goals of the organisation. Operators and marketers in the oil and gas industry face a range of challenges, associated with growing concerns about the environmental impacts of petroleum extraction (Camps, 2015; Mkutu et al., 2019), inadequate infrastructure (Enns and Bersaglio, 2016), weak governance framework (Mkutu et al., 2019), changing land use and tenure systems (Enns and Bersaglio, 2015), community-investor conflict (Mkutu et al., 2019), and widely fluctuating oil prices (Camps, 2015; Enns and Bersaglio, 2016). Many oil exploration companies have cut back on their budgets for oil exploration and development (Enns and Bersaglio, 2016). Like other industry players, oil marketers in Kenya compete in a highly competitive business environment. Effective strategy implementation is thus important for organisational survival and growth. The premise of this study is that the choice of organisational structure has implications for strategy implementation in Kenyan oil companies.

The Kenyan oil and gas industry is characterised by a large number of players which import, export, distribute and transport petroleum products. According to the Ministry of Energy (2018), Kenya has a total of 53 oil marketing companies dealing in the refining of petroleum products for Kenya. The oil and gas industry in Kenya operates under the Energy Regulation Commission, which licenses and monitors the operations of the entire retail network of 1200 petrol service stations across Kenya. As part of a downstream sector of the oil and gas industry, oil marketing companies are typically involved in the distribution and marketing of products derived from crude oil and natural gas. In reality, the Kenyan oil and gas industry mostly relies on self-regulation due to a weak regulatory framework (Mkutu et al., 2019). It is therefore imperative that oil marketing companies formulate and implement strategy effectively to meet all business challenges.

This study aims to investigate the implications of organisational structure for strategy implementation from the perspectives of employees of oil marketing companies in Kenya. Empirical studies showed that organisational structure influences the interpretation of and response to external factors (Dutt and Joseph, 2019), thereby affecting strategy formulation and implementation. However, the impacts of organisational structure on strategy implementation have been largely overlooked in the Kenyan oil and gas industry. Although petroleum products have been the main source of energy in Kenya (Longa and van der Zwaan, 2017), very few studies have been conducted in the context of Kenyan oil and gas industry. The research aim of this study is thus to examine the influence of organisational structure on strategy implementation among oil marketing companies in Kenya. The objectives of the study are as follows:

i. To determine the influence of organisational hierarchical levels on strategy implementation in oil marketing companies in Kenya.

ii. To examine the influence of organisational communication on strategy implementation in oil marketing companies in Kenya.

iii. To assess the influence of decision-making structures on strategy implementation in oil marketing companies in Kenya.

iv. To determine the influence of organisational culture on strategy implementation in oil marketing companies in Kenya.

International Journal of Management and Applied Research, 2020, Vol. 7, No. 1 


\section{Research Background: Oil and Gas Industry in Kenya}

The primary source of energy in Kenya is mostly derived from traditional biomass burning, geothermal, hydropower, and fossil fuels (Longa and van der Zwaan, 2017). A total of 33 wells were drilled in the country between 1954 and 2011 (Enns and Bersaglio, 2015). Although these wells showed clear indications of hydrocarbons, none were commercially viable (Enns and Bersaglio, 2015). Although Kenya does not export any oil, the country had a crude oil refinery but it halted its operations and it was converted into a storage facility in 2016 (Mohammed, 2019).

In 2012, London-based firm Tullow Oil announced that it had discovered oil in Turkana, a county in North West Kenya (Enns and Bersaglio, 2015). Estimates suggest that the basin could have 560 million barrels in proven and probable reserves, which would translate to 60,000 to 100,000 barrels per day of gross production (Mohammed, 2019). Major operations have been stalled because of ongoing conflict in the region which threatens oil production in Kenya (Enns and Bersaglio, 2015 and 2016). In June 2019, the Kenyan Ministry of Petroleum and Mining announced that it signed an agreement with three oil firms (Tullow Oil, Total, and Africa Oil Corp) for construction of an oil refinery in Kenya, which is expected to commence full scale oil production in 2022 (Obulutsa et al., 2019).

\section{Conceptualising Structure-Strategy relationship}

Typically, an organisation sets goals and adopts an appropriate strategy to attain those goals. The organisational structure, in turn, should support strategy implementation. An effective strategy implementation is one which fits the envisaged organisational structure. A strategy-structure fit has implications for strategy implementation and subsequent organisational performance (Child, 2015; Donaldson, 2012; ZakrzewskaBielawska 2016). Strategy determines the range of resources and levels of geographical diversity and therefore the structure required (Donaldson, 2012). For instance, if a multinational organisation wishes to penetrate its target market with high-quality standardised products with little localisation, a higher level of centralised coordination would suit such strategy (Child, 2015). On the contrary, a decentralised organisational structure is more suitable for the innovation centred exploration stage (Zakrzewska-Bielawska 2016) and start-up phase (Child, 2015), allowing a greater level of creativity and interdependence between different functional departments. Unlike centralised decision-making, where decisions are made at the top-level and passed down to lower levels, decision-making is decentralised in a flat organisational structure. In this way, regional units would be in a better position to react quickly to emerging operational issues.

Although strategies are often formulated in isolation from the factual structure, organisations would benefit from cohesive modelling, where strategies at every level of the organisation are supported by the relevant structural elements. Multinational corporations often adopt a combination of centralised operations with a varying degree of localisation, depending on organisational goals (Donaldson, 2012). For instance, Japanese corporations like Sony and Toyota, according to Child (2015), can gain competitive advantage by producing high-quality standardised products in low-cost

International Journal of Management and Applied Research, 2020, Vol. 7, No. 1 
locations, which are then marketed globally at highly competitive prices. To achieve such position a high-level of centralised coordination with limited local customisation is required. By contrast, numerous dispersed, specialised, and decentralised regional units combined with centrally coordinated worldwide operations would allow for product differentiation resulting in competitive advantage for multinational corporations; such a transnational strategy would require a relatively flat, global matrix structure (Child, 2015).

Unlike consumer goods, there are little opportunities for product differentiation for commodities deriving from oil and gas. Teece (2000) argued that industry players compete through political influence or new ways of exploring, transporting, refining and distributing oil. Hence, strategy formulation and implementation in the petroleum industry is more about efficiency and less about differentiation. Constrained by global oil depletion, competition in oil and gas discovery is intensified and consequently leads to political conflicts around allocating rights for oil production and distribution. In this context, executive decisions with regards to oil discovery and distribution would certainly affect strategy implementation. Executive and/or top level management sets the direction for organisational members to follow, and they decide what actions to take and also how to proceed. A tall hierarchy, centralised, and with top-down decision-making is often associated with a bureaucratic model of organisational culture, with a high level of formalisation and low autonomy, and unequal and authoritarian distribution of power (Janićijević, 2017). Such a bureaucratic organisational culture restricts the ability to respond quickly in a rapidly changing global business environment (Zakrzewska-Bielawska 2016). The fall of Enron has demonstrated the influence of toxic organisational culture on strategy implementation, where $15 \%$ of employees who under-performed were fired each year (Gibney, 2005). The Enron also indicated how organisational culture affects strategystructure relations because the management team managed units in a top-down, hierarchical fashion that favoured of greed rather than ethics.

Hierarchy reflects the levels of seniority and formal structure of the organisation. Child (2015) argued that having too many levels in the organisational hierarchy would create overlapping responsibilities and unnecessary interference between organisational levels. Hence, excess levels of hierarchy generally give rise to communication problems, such as withholding information within different subhierarchies or even reinterpreting instructions coming down from the upper levels in order to carve out decision-making autonomy (Child, 2015). Using Daewoo as an example, Kim (2007) shows that one-way, top-down communication creates confusion among expatriates and mid-level managers, which eventually fails to accomplish its strategic intent in transforming the organisation and expanding it overseas. Due to lack of information regarding the strategic intent of expanding overseas and relocating key personnel in foreign markets, employees felt insecure and considered overseas assignment as a sign of early retirement. Local operations began to collect information about overseas assignments through informal channels due to the lack of transparent communication. A sense of fear and job insecurity grew among managers, which led to low morale among the employees. The Daewoo case shows the importance of communication for strategy implementation and also adequate organisational transformation. Child (2015) gives an example of a restructured petroleum firm which reduced from nine to four levels of management and by doing

International Journal of Management and Applied Research, 2020, Vol. 7, No. 1 
so simplified the management structure and communication paths. As a result, flows of information and decision-making processes became more efficient leading to the greater levels of competitiveness.

\section{Research Methodology}

This study adopts a descriptive survey design using a sample drawn from employees of 31 oil marketing companies in Kenya. Distributed in 2019, 155 respondents returned the survey and the completion rate was $95 \%$, with a total of 148 respondents completing the entire questionnaire.

Table 1 summarises the demographic profile of the respondents. From a total of 148 respondents, $34 \%$ were females and $66 \%$ males. The most senior age group -- aged above 50 years old - was the largest group of the respondents $(38 \%)$ while the next largest age group was between 41 and 50 years old (36\%), followed by middle-age group, aged between 31 and 40 years old (17\%), the youngest group, between 21 and 30 years old, made up $9 \%$.

Most respondents had received a tertiary education; $51 \%$ of the respondents had undergraduate degrees, $35 \%$ of them had postgraduate degrees, and the remaining $14 \%$ had diplomas.

The work positions of the respondents are quite diverse: $17 \%$ of them are technicians, $16 \%$ are clerks, $14 \%$ are sales and marketers, $14 \%$ are researchers and developers, $13 \%$ are human resources, $10 \%$ are accountants, $9 \%$ are managers and $7 \%$ are executives.

Table 1: Demographic Profile of the Respondents

\begin{tabular}{lcc}
\hline & Frequency & Percentage (\%) \\
\hline Gender & 50 & 34 \\
Male & 98 & 66 \\
Female & & \\
Age & 14 & 9 \\
$21-30$ & 25 & 17 \\
$31--40$ & 54 & 36 \\
$41-50$ & 56 & 38 \\
Above 50 & & \\
Education & 20 & 14 \\
Diploma & 76 & 51 \\
Bachelor degree & 52 & 35 \\
Masters degree & & \\
Occupation & 25 & 17 \\
Technician & 24 & 16 \\
Clerk & 21 & 14 \\
Sales and Marketing & 20 & 14 \\
Research and Development & 19 & 13 \\
Human resources & 15 & 10 \\
Accountant & 14 & 9 \\
Manager & 10 & 7 \\
Executive &
\end{tabular}

International Journal of Management and Applied Research, 2020, Vol. 7, No. 1 
Analysis of quantitative data includes frequencies, standard deviation, and means. The findings are presented in tables. The respondents were also asked to rank each statement in the questionnaire. A five-point Likert-type scale rating from $1=$ strongly disagree to $5=$ strongly agree was used for ranking each statement.

\section{Results}

This section presents the results of field data and a discussion of findings focused on addressing the aim of the study that is to establish whether or not there is an influence of organisational structure on strategy implementation within oil marketing companies in Kenya. Results comprise the response rate, demographic information, descriptive statistics and inferential statistics. Reliability of the data collection instrument was determined by performing a reliability analysis using Cronbach's Alpha. An acceptable value for Cronbach alpha reliability is 0.7 , which was used as a benchmark in this study. For this study, an alpha value greater than 0.7 was considered reliable.

Table 2: Reliability Analysis

\begin{tabular}{lcc}
\hline Scale & Cronbach's Alpha & Number of Items \\
\hline Organisational Hierarchical Levels & 0.787 & 2 \\
Organisational Communication & 0.781 & 2 \\
Decision-Making Structures & 0.797 & 2 \\
Organisation Culture & 0.701 & 2 \\
Strategy Implementation & 0.758 & 2 \\
\hline
\end{tabular}

From the results presented in Table 2: organisational hierarchical levels (0.787), organisational communication (0.781), decision-making structures (0.797), organisation culture $(0.701)$, and strategy implementation $(0.758)$-- it can be concluded that all alpha values are reliable because they all above 0.7 .

\subsection{Descriptive Statistics}

Respondents shared their opinions on the statements seeking to rate the extent to which hierarchical levels affects strategy implementation in their organisation.

Table 3: Effect of Hierarchical Levels on Strategy Implementation

\begin{tabular}{|c|c|c|c|c|c|c|c|}
\hline Statement & 1 & 2 & 3 & 4 & 5 & Mean & $\begin{array}{l}\text { Std. } \\
\text { Dev }\end{array}$ \\
\hline $\begin{array}{l}\text { Having many hierarchical levels is the } \\
\text { most efficient way of strategy } \\
\text { implementation }\end{array}$ & 9 & 14 & 19 & 68 & 38 & 3.75 & 0.77 \\
\hline $\begin{array}{l}\text { Fewer hierarchical levels is the most } \\
\text { efficient way of strategy } \\
\text { implementation }\end{array}$ & 13 & 18 & 18 & 72 & 27 & 3.55 & 0.75 \\
\hline
\end{tabular}

Respondents indicated that many hierarchical levels lead to efficiency in implementation of strategy $(\mathrm{M}=3.75)$ and fewer hierarchical levels also lead to efficiency in implementation of strategy $(\mathrm{M}=3.55)$. The findings concur with findings

International Journal of Management and Applied Research, 2020, Vol. 7, No. 1 
of Zakrzewska-Bielawska (2016) who noted that in a flat hierarchy, the number of employees who report to a single manager is fewer and this facilitates proper supervision and monitoring of employees which results in a narrower span of control. In a taller hierarchy, by contrast, a large number of employees report to each manager and therefore the span of control is wide; in this structure, managers are unable to provide close supervision leading to greater freedom levels for every employee.

Respondents shared their opinions on the statements relating to the impact of organisational communication on strategy implementation in their organisations.

Table 4: Effect of Organisation Communication on Strategy Implementation

\begin{tabular}{lcccccccc}
\hline \multicolumn{1}{c}{ Statement } & $\mathbf{1}$ & $\mathbf{2}$ & $\mathbf{3}$ & $\mathbf{4}$ & $\mathbf{5}$ & Mean & $\begin{array}{l}\text { Std. } \\
\text { Dev }\end{array}$ \\
\hline $\begin{array}{l}\text { Vertical communication is most } \\
\text { efficient in strategy implementation }\end{array}$ & 15 & 18 & 26 & 55 & 34 & 3.50 & 0.59 \\
$\begin{array}{l}\text { Horizontal communication is most } \\
\text { efficient in strategy implementation }\end{array}$ & 12 & 15 & 20 & 62 & 39 & 3.68 & 0.71 \\
\hline
\end{tabular}

Similarly to the preceding results in Table 3, respondents believe that horizontal communication can lead to efficient implementation of strategy $(M=3.68)$ and vertical communication can also be efficient in implementation of strategy $(M=3.50)$. These results concur with Janićijević (2017) who noted that employees who are in companies that can easily access management through a communication climate that is open and supportive have a tendency to outperform those whose environment is restrictive communication.

Respondents shared their opinions on the statements related to decision making structures as they affect strategy implementation in their organisations.

Table 5: Effect of Decision-Making Structures on Strategy Implementation

\begin{tabular}{lllllllll}
\hline Statement & $\mathbf{1}$ & $\mathbf{2}$ & $\mathbf{3}$ & $\mathbf{4}$ & $\mathbf{5}$ & Mean & $\begin{array}{l}\text { Std. } \\
\text { Dev }\end{array}$ \\
\hline $\begin{array}{l}\text { Centralized decision making is more } \\
\text { cost effective than decentralized } \\
\text { decision making }\end{array}$ & 8 & 13 & 16 & 68 & 43 & 3.84 & 0.81 \\
$\begin{array}{l}\text { A centralized structure slows down } \\
\text { decision making and strategy } \\
\text { implementation in the organisation }\end{array}$ & 10 & 15 & 20 & 57 & 46 & 3.77 & 0.73 \\
\hline
\end{tabular}

Respondents indicated that centralized decision making is more cost effective than decentralized decision making $(\mathrm{M}=3.84)$ and a centralized structure slows down decision making and strategy implementation $(\mathrm{M}=3.77)$. This finding relates to those of Ketokiv (2004) who argued that the decision making process can be quicker and it is believed that organisations that are decentralized provide a great level of fairness to its workforce.

Respondents shared their opinions on the statements below related to the impact of organisation culture on strategy implementation in their organisations.

International Journal of Management and Applied Research, 2020, Vol. 7, No. 1 
Organisational Structure and Strategy Implementation: Empirical Evidence from Oil Marketing Companies in Kenya

Table 6: Effects of Organisation Culture on Strategy Implementation

\begin{tabular}{|c|c|c|c|c|c|c|c|}
\hline Statement & 1 & 2 & 3 & 4 & 5 & Mean & $\begin{array}{l}\text { Std. } \\
\text { Dev }\end{array}$ \\
\hline $\begin{array}{l}\text { Management of organisation culture is } \\
\text { the critical component in strategy } \\
\text { implementation }\end{array}$ & 9 & 15 & 18 & 49 & 57 & 3.878 & 0.811 \\
\hline $\begin{array}{l}\text { Organisation culture enhances } \\
\text { strategy implementation in the } \\
\text { organisation }\end{array}$ & 10 & 17 & 20 & 70 & 31 & 3.642 & 0.749 \\
\hline
\end{tabular}

Results show that respondents overall believe that the management of organisation culture is critical for implementation of strategy $(\mathrm{M}=3.878)$ and organisation culture also enhances implementation of strategy in the organisation $(\mathrm{M}=3.642)$. This findings concur with Klein (2011) who noted that the culture of an organisation is a way of attaining competitive advantage, it was found that the norms in a culture have a tendency of fairly and consistently influencing quality regardless of the strategy that is adopted by the company.

Respondents gave their opinion on statements relating to strategy implementation.

Table 7: Strategy Implementation and targets setting in organisations

\begin{tabular}{|c|c|c|c|c|c|c|c|}
\hline Statement & 1 & 2 & 3 & 4 & 5 & Mean & $\begin{array}{l}\text { Std. } \\
\text { Dev }\end{array}$ \\
\hline $\begin{array}{l}\text { Workers having performance targets } \\
\text { would help in strategy } \\
\text { implementation }\end{array}$ & 10 & 15 & 18 & 66 & 39 & 3.736 & 0.759 \\
\hline $\begin{array}{l}\text { The organisation has set targets that } \\
\text { it strives to achieve which are } \\
\text { applicable across all departments of } \\
\text { the organisation. }\end{array}$ & 8 & 17 & 21 & 55 & 47 & 3.784 & 0.725 \\
\hline
\end{tabular}

From Table 7, the respondents overall agree with both statements: workers should have performance targets $(M=3.736)$ and organisation should set targets applicable across all departments of the organisation $(\mathrm{M}=3.784)$.

\section{Discussion}

Organisational structure influences the ability to respond quickly to changes in external environment as well as resource management and development. The taller the hierarchy, the longer the chain of command and the more resources needed to implement strategy effectively. Such an organisational structure has a hierarchical distribution of power and that leads to an organisational culture that is more bureaucratic and authoritarian (Janićijević, 2017). The survey results indicate that employees in Kenyan oil marketing companies largely agree with the view that organisational structure affects strategy implementation. For them, hierarchy is an effective means for executing strategy.

International Journal of Management and Applied Research, 2020, Vol. 7, No. 1 
The respondents perceive that centralised decision making is more cost-effective than decentralised, but they also considered that centralised decision making process is more time-consuming and lengthy. It is interesting to note that the respondents consider both vertical and horizontal communication as effective ways of communication in implementing strategies. However, little is known regarding the reasons behind this. One may speculate that this is due to the use of a combination of vertical and horizontal communication in their companies when disseminating information and implementing strategies. Future research could investigate this subject matter with regards to the factors that lead the respondents to consider both vertical and horizontal communication effective.

The respondents mostly agree and strongly agree with the view that organisational culture plays an important role in strategy implementation. The respondents also revealed that their companies have set performance targets for individuals and functional departments. Nonetheless, it is unclear whether organisational culture in Kenyan oil marketing firms is encouraging or discouraging employee behaviours towards performance management system in their firms. A follow-up focus group or in-depth interview may help to understand their views further.

\section{Conclusion}

The relationship between organisational structure and strategy implementation has an influence on communication, culture, and decision-making. This study presents an exploratory view regarding the perception of the workforce in oil marketing companies in Kenya towards the strategy-structure relationship. The majority (73\%) of the oil marketing companies are multinational companies (Ministry of Energy, 2018), and these companies face the challenge of thinking and acting both globally and locally (Cohen, 2010). Successful oil marketing companies attempt to implement an organisational structure that combines centralised decision making and, at the same time, ensures that their employees have the autonomy to make swift decisions.

The discussion presented in this study does not cover all the issues related to the concept of the strategy-structure relationship, and the study is not without its limitations. First, the impact of structure on strategy and vice versa was determined based on the opinions of research respondents, which are subjective by their nature. Future research could be conducted into financial performance and other quantifiable performance indicators in order to investigate the statistical relationship between organisational performance and strategy-structure relationship. Second, the data represents a snapshot of a particular time period, thereby limiting the perceived mutual impact of strategy and structure in terms of time perspective. Thus, further research could be conducted into this research topic with a more longitudinal analysis. It would also be insightful to undertake research on the impact of other relevant variables such as organisational life cycle and technological advancement.

International Journal of Management and Applied Research, 2020, Vol. 7, No. 1 


\section{References}

1. Camps, N. (2015), "An Exploratory Study of Skills Shortages within the Oil and Gas Industry in Scotland", International Journal of Management and Applied Research, Vol. 2, No. 3, pp. 130-143. https://doi.org/10.18646/2056.23.15-014

2. Child, J. (2015), Organisation; Contemporary Principles and Practice, $2^{\text {nd }}$ ed., UK: John Wiley \& Sons.

3. Cohen, S. L. (2010), "Effective global leadership requires a global mindset", Industrial and Commercial Training, Vol. 42, No. 1, pp.3-10. https://doi.org/10.1108/00197851011013652

4. Donaldson, L. (2012), "Chapter 22: Design Structure to Fit Strategy”, in: Locke, E. A. (Ed), Handbook of Principles of Organizational Behavior: Indispensable Knowledge for Evidence-Based Management, $2^{\text {nd }}$ ed., UK: John Wiley \& Sons, Ltd, pp. 405-424. https://doi.org/10.1002/9781119206422.ch22

5. Dutt; N. and Joseph, J. (2019), "Regulatory uncertainty, corporate structure, and strategic agendas: Evidence from the U.S. Renewable electricity industry", Academy of Management Journal, Vol. 62, No. 3, pp. 800-827. https://doi.org/10.5465/amj.2016.0682

6. Enns, C. and Bersaglio, B. (2015), "Enclave oil development and the rearticulation of citizenship in Turkana, Kenya: Exploring crude citizenship", Geoforum, Vol. 67, pp. 78-88. https://doi.org/10.1016/j.geoforum.2015.10.010

7. Enns, C. and Bersaglio, B. (2016), "Pastoralism in the time of oil: Youth perspectives on the oil industry and the future of pastoralism in Turkana, Kenya", Extractive Industries and Society, Vol. 3, No. 1, pp. 160-170. https://doi.org/10.1016/j.exis.2015.11.003

8. Gibney, A. (2005), Enron: The smartest guys in the room [motion picture], United States: Magnolia Pictures.

9. Janićijević, N. (2017), "Organizational Models As Configurations Of Structure, Culture, Leadership, Control, And Change Strategy”, Economic Annals, Vol. 62, No. 213, pp. 67-92. https://doi.org/10.2298/EKA1713067J

10. Ketokiv, M.A. (2004), "Strategic, structural contingency and institutional explanations in the adoption of innovative manufacturing practices", Journal of Operations Management, Vol. 22, No. 1, pp. 63-89. https://doi.org/10.1016/j.jom.2003.12.002

11. Klein, A. (2011), "Corporate culture: its value as a resource for competitive advantage", Journal of Business Strategy, Vol. 32, No. 2, pp. 21-28. https://doi.org/10.1108/02756661111109743

International Journal of Management and Applied Research, 2020, Vol. 7, No. 1 
12. Kim, D. J. (2007), "Falls from Grace and Lessons from Failure: Daewoo and Medison", Long Range Planning, Vol. 40, No. 4-5, pp. 446-464. https://doi.org/10.1016/j.lrp.2007.06.003

13. Longa, F. D. and van der Zwaan, B. (2017), "Do Kenya's climate change mitigation ambitions necessitate large-scale renewable energy deployment and dedicated low-carbon energy policy?", Renewable Energy, Vol. 113, pp. 15591568. https://doi.org/10.1016/j.renene.2017.06.026

14. Ministry of Energy (2018), Downstream [Online], available from: http://energy.go.ke/?p=323 [Accessed on 11 November 2019].

15. Mohammed, O. (2019), "Kenya says crude oil capacity insufficient for refinery", Reuters [Online] available from: https://www.reuters.com/article/us-kenyaoil/kenya-says-crude-oil-capacity-insufficient-for-refinery-idUSKCN1Q80JZ [Accessed on 11 November 2019].

16. Mkutu, K., Mkutu, T., Marani, M., and Ekitela, A. L. (2019), "New Oil Developments in a Remote Area: Environmental Justice and Participation in Turkana, Kenya", The Journal of Environment \& Development, Vol. 28, No. 3, pp. 223-252. https://doi.org/10.1177/1070496519857776

17. Obulutsa, G.; Miriri, D. and Nasralla, S. (2019), "Kenya signs milestone crude processing deal with oil firms", Reuters [Online] available from: https://af.reuters.com/article/investingNews/idAFKCN1TQ1LG-OZABS [Accessed on 11 November 2019].

18. Teece, D. J. (2000), "Strategies for managing knowledge assets: the role of firm structure and industrial context", Long range planning, Vol. 33, No. 1, pp. 35-54. https://doi.org/10.1016/S0024-6301(99)00117-X

19. Zakrzewska-Bielawska, A. (2016), "Perceived mutual impact of strategy and organizational structure: Findings from the high-technology enterprises", Journal of Management \& Organization, Vol. 22, No. 5, pp. 599-622. https://doi.org/10.1017/jmo.2015.55 


\section{Appendix I: Questionnaire}

\section{Part A: Respondents Information}

1. Age of the respondent
21-30 years
[ ] 31 to 40 years [ ] 41 to 50 years [ ] above 50 years [ ]

2. Gender of the respondent?
Male
[ ]
Female
[ ]

3. What is your highest level of education?
Postgraduate []
Degree [ ]
Diploma [ ]

4. What is your role in the organisation?

Executive [ ] Management [] Clerk [ ] HR [ ] Accountant [ ]

Sales and Marketing [ ] Technician [ ] Research and Development [ ]

\section{Part B: Hierarchical Levels and Strategy Implementation}

What is your level of agreement with the following statements relating to hierarchical levels affecting the strategy implementation of your organisation?

$1=$ strongly disagree, $5=$ strongly agree

\begin{tabular}{|l|lll|l|l|l|l|l|}
\hline & Statement & & 1 & 2 & 3 & 4 & 5 \\
\hline a. & $\begin{array}{l}\text { Many hierarchical levels is most efficient in strategy } \\
\text { implementation }\end{array}$ & & & & \\
\hline b. & $\begin{array}{l}\text { Few hierarchical levels is most efficient in strategy } \\
\text { implementation }\end{array}$ & & & \\
\hline
\end{tabular}

\section{Part C: Organisational Communication and Strategy Implementation}

What is your level of agreement with the following statements relating to organisational communication affecting the strategy implementation of your organisation?

$1=$ strongly disagree, $5=$ strongly agree

\begin{tabular}{|l|l|l|l|l|l|l|}
\hline & Statement & 1 & 2 & 3 & 4 & 5 \\
\hline a. & $\begin{array}{l}\text { Vertical communication is most efficient in strategy } \\
\text { implementation }\end{array}$ & & & & \\
\hline b. & $\begin{array}{l}\text { Horizontal communication is most efficient in strategy } \\
\text { implementation }\end{array}$ & & & & \\
\hline
\end{tabular}

Part D: Decision Making Structures and Strategy Implementation

What is your level of agreement with the following statements relating to decision making structures affecting the strategy implementation of your organisation?

$1=$ strongly disagree, $5=$ strongly agree

\begin{tabular}{|l|l|l|l|l|l|l|}
\hline & Statement & 1 & 2 & 3 & 4 & 5 \\
\hline a. & $\begin{array}{l}\text { Centralized decision making is more cost effective than } \\
\text { decentralized decision making }\end{array}$ & & & & \\
\hline b. & $\begin{array}{l}\text { A centralized structure slows down decision making and strategy } \\
\text { implementation in the organisation }\end{array}$ & & & \\
\hline
\end{tabular}

International Journal of Management and Applied Research, 2020, Vol. 7, No. 1 
Part E: Organisation Culture and Strategy Implementation

What is your level of agreement with the following statements relating to organisation culture affecting the strategy implementation of your organisation?

$1=$ strongly disagree, $5=$ strongly agree

\begin{tabular}{|l|l|l|l|l|l|l|}
\hline & Statement & 1 & 2 & 3 & 4 & 5 \\
\hline a. & $\begin{array}{l}\text { Organisation culture management are critical components of } \\
\text { strategy implementation }\end{array}$ & & & \\
\hline b. & $\begin{array}{l}\text { Organisation culture enhance strategy implementation in the } \\
\text { organisation }\end{array}$ & & & \\
\hline
\end{tabular}

\section{Part F: Strategy Implementation}

What is your level of agreement with the following statements relating to strategy implementation?

$1=$ strongly disagree, $5=$ strongly agree

\begin{tabular}{|l|l|l|l|l|l|l|}
\hline & Statement & 1 & 2 & 3 & 4 & 5 \\
\hline a. & $\begin{array}{l}\text { Workers have performance targets that help in implementation } \\
\text { strategy }\end{array}$ & & & & \\
\hline b. & $\begin{array}{l}\text { The organisation has set targets that it strives to achieve which } \\
\text { are applicable across all departments of the organisation. }\end{array}$ & & & & \\
\hline
\end{tabular}

